\title{
Effect of sitagliptin on blood glucose control in patients with type 2 diabetes mellitus who are treatment naive or poorly responsive to existing antidiabetic drugs: the JAMP study
}

Hiroshi Sakura ${ }^{1 *}$, Naotake Hashimoto ${ }^{2}$, Kazuo Sasamoto ${ }^{3}$, Hiroshi Ohashi ${ }^{4}$, Sumiko Hasumi ${ }^{5}$, Noriko Ujihara ${ }^{6}$, Tadasu Kasahara ${ }^{7}$, Osamu Tomonaga ${ }^{8}$, Hideo Nunome ${ }^{9}$, Masashi Honda ${ }^{10}$, Yasuhiko Iwamoto ${ }^{11}$ and for the JAMP Study Investigators

\begin{abstract}
Background: To investigate the ameliorating effect of sitagliptin, a dipeptidyl peptidase-4 inhibitor, on blood glucose control in patients with type 2 diabetes mellitus who were previously untreated with or who have a poor responsive to existing antidiabetic drugs.

Methods: Sitagliptin (50 mg/day) was added on to the pre-existing therapy for type 2 diabetes and changes in the glycated hemoglobin (HbA1c) level after 3 months of treatment were compared with the baseline and performed exploratory analysis.

Results: $\mathrm{HbA} 1 \mathrm{c}$ levels were significantly decreased after 1 month of treatment compared to baseline, with a mean change in $\mathrm{HbA} 1 \mathrm{c}$ level from baseline of $-0.73 \%$ (range, -0.80 to -0.67 ) in the entire study population at 3 months. Patients who received a medium dose of glimepiride showed the least improvement in $\mathrm{HbA} 1 \mathrm{c}$ levels. The percentage of patients who achieved an $\mathrm{HbA1c}$ level of $<7.0 \%$ significantly increased after 1 month of treatment, reaching $53.1 \%$ at 3 months. The percentage of patients who achieved a fasting blood glucose level of $<130 \mathrm{mg} / \mathrm{dL}$ significantly increased after 1 month of treatment, reaching $50.9 \%$ at 3 months.

Conclusions: Sitagliptin improved the $\mathrm{HbA1c}$ level and rate of achieving the target control levels in patients with type 2 diabetes mellitus who were previously untreated with, or poorly responsive to, existing antidiabetic drugs. Thus, sitagliptin is expected to be useful in this patient group. However, the additional administration of sitagliptin in patients treated with medium-dose glimepiride only slightly improved blood glucose control when corrected for baseline HbA1c level.
\end{abstract}

Keywords: Sitagliptin, Diabetes mellitus, DPP-4 inhibitor, HbA1c, Glimepiride

\footnotetext{
* Correspondence: sakuragm@dnh.twmu.ac.jp

${ }^{1}$ Department of Medicine, Medical Center East, Tokyo Women's Medical

University School of Medicine , 2-1-10 Nishiogu, Arakawa-ku, Tokyo 116-8567,

Japan

Full list of author information is available at the end of the article
} 


\section{Background}

The 2012 National Health and Nutrition Survey conducted by the Ministry of Health, Labour and Welfare of Japan (MHLW) estimated that approximately 20.5 million people were strongly suspected of having diabetes mellitus; these patients are considered the at-risk group of individuals in whom diabetes mellitus cannot be ruled out [1]. An increasing amount of patients strongly suspected of having diabetes mellitus are currently being treated with existing antidiabetic drugs (men, 65.9\% and women, 64.3\%) [1]. However, existing antidiabetic drugs have various drawbacks, including insufficient efficacy, short-lasting effect [2], body weight increase and inconvenient administration. Thus, new drugs that have a different mechanism of action and that show improved efficacy, safety and tolerability are required.

Dipeptidyl peptidase-4 (DPP-4) inhibitors exhibit antidiabetic effects by stimulating insulin secretion through highly selective inhibition of DPP-4, an enzyme that inactivates incretins such as glucagon-like peptide 1 and gastric inhibitory polypeptide via a mechanism different from that of conventional hypoglycemic drugs. Many reports have demonstrated the superior efficacy and safety of DPP-4 inhibitors [3-5], among which sitagliptin was the first to gain approval in Japan in 2009. Many reports of sitagliptin had published, but we have examined the additional effect of sitagliptin in 7 pre-existing therapy groups. Treatment of these patients often includes other antidiabetic medications because they often have diverse complications. The objective of this study is to investigate the ameliorating effect of sitagliptin on blood glucose control in patients with type 2 diabetes mellitus, who were previously untreated with, or who had a poor responsive to, existing antidiabetic drugs.

\section{Methods}

\section{Study design}

This open-label, central registration, multi-center, prospective observational study was conducted at the Tokyo Women's Medical University Hospital and 69 collaborating institutions in Japan. Patients were enrolled from 1 January 2011 to 30 June 2013, and followed up until 30 June 2014. This study was conducted with the approval of the ethic committee of the Tokyo Women's Medical University (UMIN000019154).

\section{Study subjects}

The study subjects were male or female, 20 years of age or older, and outpatients with type 2 diabetes mellitus and inadequately controlled blood glucose levels (a glycated hemoglobin (HbA1c) level of $\geq 6.9 \%$ (52 mmol/ $\mathrm{mol}$ ) or a fasting blood glucose level of $\geq 130 \mathrm{mg} / \mathrm{dL}$ [6] during the observation period) after at least 1 month of receiving diet/exercise therapy or/and oral antidiabetic drug therapy.

The participants were treated with diet and exercise therapy, low-dose glimepiride (0.5-1 mg), medium-dose glimepiride (1.5-2 mg), biguanides, thiazolidines, $\alpha$ glucosidase inhibitors or two or more of these drugs in combination during the observation period. And patients treated with more than $2 \mathrm{mg}$ of glimepiride or other SUs were excluded from the study.

The all patients provided written informed consent before participation.

Patients who met any of the following criteria were excluded from the study: (i) history of severe ketosis, diabetic coma or pre-coma within the past 6 months; (ii) severe infection before or after surgical treatment, or serious external injury; (iii) pregnancy, possible pregnancy or lactation; (iv) moderate renal impairment (serum creatinine level $\geq 1.5 \mathrm{mg} / \mathrm{dL}$ in men and $\geq 1.3 \mathrm{mg} /$ $\mathrm{dL}$ in women); (v) patients on insulin therapy; (vi) patients on treatment with rapid-acting insulin secretagogues; (vii) history of allergy to the ingredients of the study drug; and (viii) a medical reason that makes the patient unsuitable for participation in the study as judged by the investigator.

Treatment with (v) and/or (vi) were not covered by national health insurance at the time of setting the study protocol.

\section{Treatments}

The pre-existing therapy for type 2 diabetes were not changed during the observation period and entire study period (for the first 3 months after add-on sitagliptin). Thereafter, sitagliptin (50 mg) was administered once daily as a first-line treatment (single-drug therapy) or as an additional treatment (combination therapy; Fig. 1). During the 3-month period from the initiation of sitagliptin treatment (baseline), administration of sitagliptin was continued without the addition of any other drugs or dose increases. At 3 months, the sitagliptin dose was increased from 50 to $100 \mathrm{mg} /$ day and other antidiabetic drugs were added, changed or discontinued at the investigator's discretion. No restrictions were imposed on the use of drugs for treating concurrent diseases, but dose changes or the addition of new drugs was avoided whenever possible during the study period.

\section{Evaluation}

All end points were defined in the study protocol prior to implementation of the study. The primary end point was the change in HbA1c level at 3 months from baseline. The secondary end points were as follows: the percentage of patients who achieved a normal HbA1c level $(<7.0 \%, 53 \mathrm{mmol} / \mathrm{mol} \mathrm{[6])}$ and the percentage of patients who achieved a normal fasting blood glucose level 


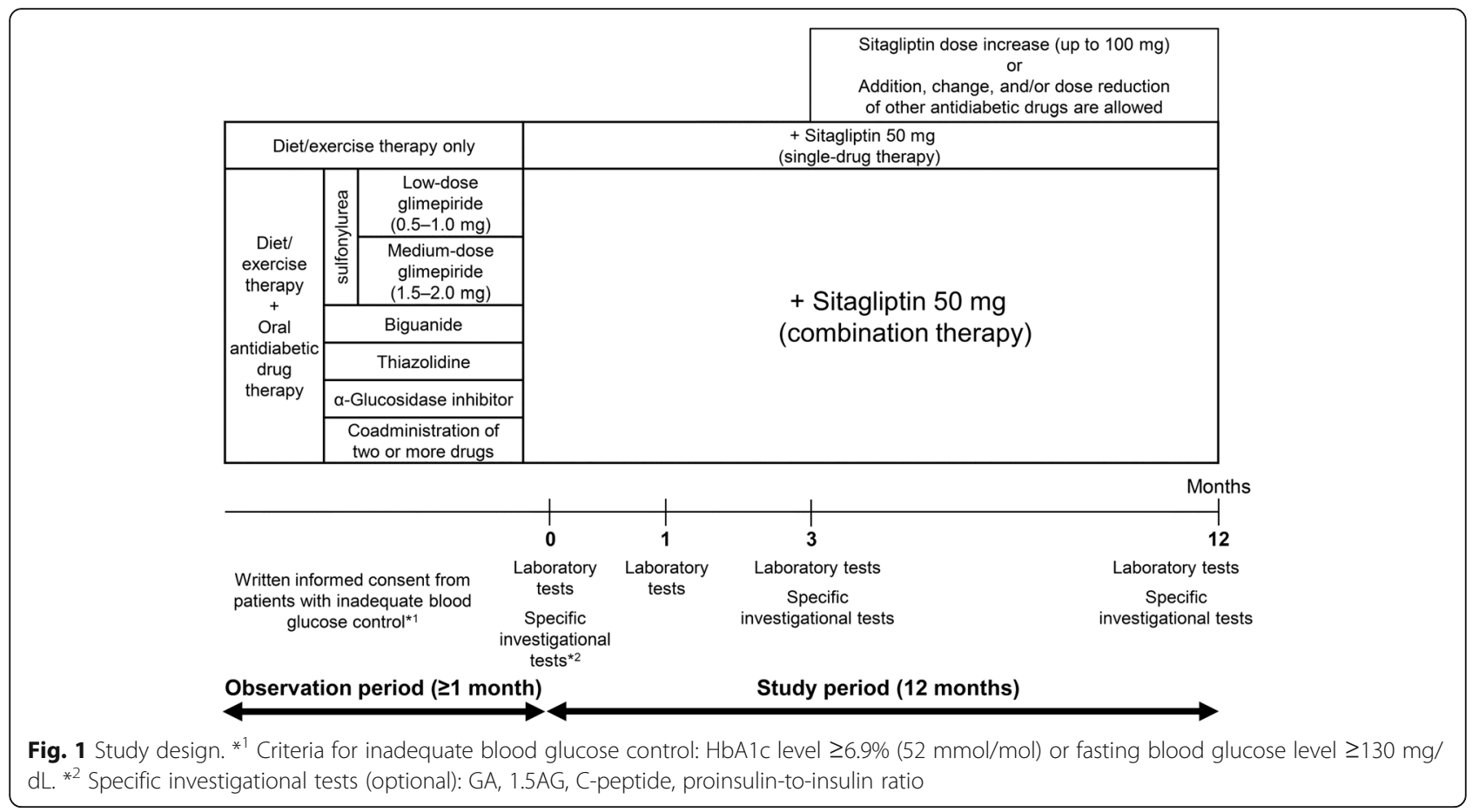

$(<130 \mathrm{mg} / \mathrm{dL})$ at 1,3 and 12 months after the start of treatment; changes in $\mathrm{HbA} 1 \mathrm{c}$ from baseline at 1 and 12 months after starting treatment; and fasting blood glucose level, homeostatic model of assessment- $\beta$ index and blood lipid levels (low-density lipoprotein cholesterol [LDL-C], triglycerides [TG], and high-density lipoprotein cholesterol [HDL-C]) at 3 and 12 months after starting treatment.

In addition, the HbA1c level at 3 months of treatment and the change in HbA1c level from baseline were calculated for each patient group classified according to the concomitant drug used. The approximate linear correlation between the baseline $\mathrm{HbA1c}$ level and the change in HbA1c level after 3 months of treatment was examined statistically using an exploratory approach. Multiple linear regression analysis was performed using the deviation from the correlation line as the dependent variable. Safety assessments included the incidence of adverse drug reactions and hypoglycemia during the study period.

At the start of the study in 2011, HbA1c values were expressed in The Japan Diabetes Society levels, the standard system in Japan, but were changed to National Glycohemoglobin Standardization Program (NGSP) system values at the end of the study in accordance with the "Report of the Committee on the Classification and Diagnostic Criteria of Diabetes Mellitus (Revision for International Harmonization)," issued by The Japan Diabetes Society [7]. Pursuant to the above change, the lower limit of inadequate blood glucose control was also changed. Therefore, patients with an HbA1c level of $\geq 6.9 \%$ ( $52 \mathrm{mmol} / \mathrm{mol}$ ) were enrolled at the start of the study, but at the data analysis stage, the percentage of patients who achieved the target HbA1c level of $\geq 7.0 \%$ (53 $\mathrm{mmol} / \mathrm{mol})$ or $<7.0 \%(53 \mathrm{mmol} / \mathrm{mol})$ was calculated.

\section{Statistical analysis}

Data analysis was performed using IBM SPSS Statistics 22.0 for Windows (IBM Japan, Ltd.). Observed values were analyzed using a paired $t$ test, while a betweengroup comparison of changes was performed using analysis of variance. The chi-square test was used to analyze the percentage of patients who achieved the HbA1c target level, and correlation was evaluated using Pearson's test. The factors that affect the fasting blood glucoselowering effect were evaluated using simple and multiple regression analyses, with the significance level set at 5\% (two-sided). Demographic characteristics are presented as the mean \pm standard deviation (SD), and the observed values are presented as the mean \pm standard error (SE). Changes are presented as the mean (95\% confidence interval $[\mathrm{CI}])$.

\section{Results}

Figure 2 shows the flow diagram of the patient enrollment in the study. Of the 779 patients with T2DM enrolled, 651 were included in the Efficacy analysis (Diet/ exercise therapy, 189; Low-dose glimepiride, 72; Mediumdose glimepiride, 50; Biguanide, 99; Thiazolidine, 38; $\alpha$-GI, 18; Combination therapy, 185). Table 1 shows the baseline 


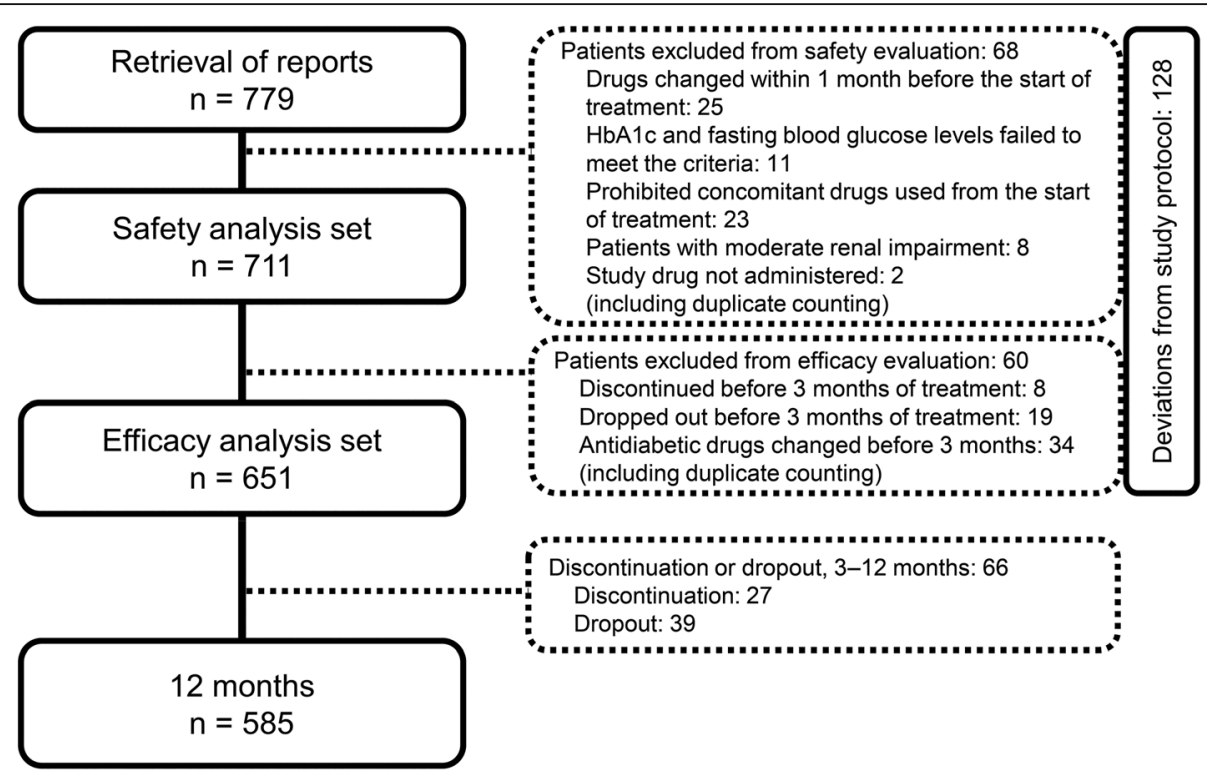

Fig. 2 Patient enrollment flow diagram

demographics of the 651 patients who were classified according to the concomitant drug used and evaluated to determine treatment efficacy. Past or concurrent illnesses in the entire study population are also presented in Table 1. There were $22(3.4 \%)$ participants at 3 months and $37(5.7 \%)$ participants at 12 months reported as poor adherence of sitagliptin.

The HbA1c level significantly decreased after one month of treatment compared to baseline $(p<0.05)$, and this reduction was maintained throughout 12 months of treatment (Additional flile 1: Figure S1). The change $(95 \% \mathrm{CI})$ in HbA1c level from baseline in the entire patient population was $-0.73 \%(-0.80$ to -0.67$)$ at 3 months of treatment. There was no significant difference in the change in HbA1c level between the patient groups treated with different concomitant drugs (Fig. 3 and Additional file 3).

The HbA1c level normalization rate, expressed as the percentage of patients who achieved an HbA1c level of $<7.0 \%(53 \mathrm{mmol} / \mathrm{mol})$, significantly increased at $1 \mathrm{month}$ compared to baseline $(p<0.05)$, reaching an increase in $53.1 \%$ at 3 months (Additional flile 2: Figure S2). The fasting blood glucose normalization rate, calculated as the percentage of patients who achieved a fasting blood glucose level of $<130 \mathrm{mg} / \mathrm{dL}$, significantly increased at 1 month compared to baseline $(p<0.05)$, reaching an increase of $50.9 \%$ at 3 months (S2). We enrolled patients who meet the criteria of a glycated hemoglobin (HbA1c) level of $\geq 6.9 \%$ ( $52 \mathrm{mmol} / \mathrm{mol}$ ) or a fasting blood glucose level of $\geq 130 \mathrm{mg} / \mathrm{dL}$ [6] during the observation period. Consequently, this study include patients who were achieved the HbA1c goal/or the fasting blood glucose goal at baseline.
Table 2 shows the changes $(95 \% \mathrm{CI})$ in most laboratory parameters at 3 and 12 months after the start of treatment compared with baseline. Improvement was observed in many of the diabetes mellitus-related parameters.

The factors that affect the blood glucose-lowering effect of sitagliptin were also investigated. A negative correlation $(R=-0.528, p<0.05)$ was observed between the baseline HbA1c level and the change in HbA1c level from baseline to 3 months (S3). Related factors other than baseline $\mathrm{HbA1c}$ level were also investigated. For this purpose, the approximate linear correlation between the baseline HbA1c level and that at 3 months of treatment was calculated. A single regression analysis was performed using the deviation from the correlation line as the dependent variable. The results indicate that age, body mass index, mean blood pressure and concomitant administration of medium-dose glimepiride significantly affected sitagliptin efficacy (Table 3). Using the factors that showed a significant effect, multiple regression analysis was performed on the deviation from the approximate linear correlation. Only medium-dose glimepiride significantly affected sitagliptin efficacy ( $p=0.017$; Table 3 ).

Table 4 shows the changes in anti-diabetic medication during the study and 86 patients were increased the dose of sitagliptin after the 3 months of follow-up visits.

Adverse events observed in the 711 safety-evaluable patients included clinical symptoms in 37 patients and laboratory abnormalities in 18 patients (Table 5). 19 out of 55 patients discontinued administration of sitagliptin because of the adverse event. Four of these events, anemia (sitagliptin single-drug group), hypoglycemia (multipledrug co-administration group, low-dose glimepiride 
Table 1 Patient demographic characteristics

\begin{tabular}{|c|c|c|c|c|c|c|c|c|}
\hline \multirow[t]{2}{*}{ Group Parameter } & \multirow[b]{2}{*}{ Overall } & \multirow{2}{*}{$\begin{array}{l}\text { (Sitagliptin only) } \\
\text { Diet/exercise therapy }\end{array}$} & \multicolumn{6}{|l|}{ +Sitagliptin (combination therapy) } \\
\hline & & & Low-dose glimepiride (0.5-1.0 mg) & $\begin{array}{l}\text { Medium-dose glimepiride } \\
(1.5-2.0 \mathrm{mg})\end{array}$ & Biguanide & Thiazolidine & $a-G l$ & $\begin{array}{l}\text { Coadministration of } \\
\text { two or more drugs }\end{array}$ \\
\hline$n$ & 651 & 189 & 72 & 50 & 99 & 38 & 18 & 185 \\
\hline Age (y) & $63.8 \pm 11.8$ & $64.6 \pm 12.7$ & $68.1 \pm 11.1$ & $65.3 \pm 11.2$ & $59.3 \pm 11.4$ & $64.3 \pm 12.2$ & $63.9 \pm 11.7$ & $63.2 \pm 10.8$ \\
\hline Sex (male \%) & $434(66.7)$ & $121(64.0)$ & $44(61.1)$ & $37(74.0)$ & $72(72.7)$ & $27(71.1)$ & $13(72.2)$ & $120(64.9)$ \\
\hline BMI $\left(\mathrm{kg} / \mathrm{m}^{2}\right)$ & $25.2 \pm 4.2$ & $24.5 \pm 4.1$ & $24.3 \pm 4.0$ & $24.5 \pm 3.5$ & $25.8 \pm 3.6$ & $26.4 \pm 7.1$ & $25.9 \pm 3.9$ & $25.7 \pm 4.1$ \\
\hline Abdominal circumference (cm) & $88.3 \pm 11.1$ & $87.3 \pm 10.7$ & $88.7 \pm 10.7$ & $85.1 \pm 8.2$ & $88.9 \pm 9.0$ & $92.9 \pm 21.4$ & $92.4 \pm 7.2$ & $87.9 \pm 10.1$ \\
\hline Disease duration (y) & $8.8 \pm 6.7$ & $6.2 \pm 5.7$ & $8.2 \pm 6.4$ & $10.2 \pm 8.1$ & $9.4 \pm 6.8$ & $10.5 \pm 7.1$ & $8.7 \pm 5.7$ & $10.5 \pm 6.5$ \\
\hline Smoking habit (\%) & $143(22.7)$ & $32(17.4)$ & $14(20.3)$ & $16(34.0)$ & $26(27.1)$ & $5(13.5)$ & $4(22.2)$ & $46(25.6)$ \\
\hline Drinking habit (\%) & $301(48.1)$ & $79(42.5)$ & $31(47.0)$ & $33(68.8)$ & $51(53.1)$ & $19(52.8)$ & $10(55.6)$ & $78(44.3)$ \\
\hline HbA1c (\%) & $7.86 \pm 1.07$ & $7.67 \pm 1.09$ & $7.74 \pm 0.86$ & $8.23 \pm 1.31$ & $8.05 \pm 1.10$ & $7.64 \pm 0.74$ & $7.26 \pm 0.76$ & $8.00 \pm 1.04$ \\
\hline $\begin{array}{l}\text { Converted mean } \mathrm{HbA} 1 \mathrm{c} \\
(\mathrm{mmol} / \mathrm{mol})\end{array}$ & 62 & 60 & 61 & 66 & 64 & 60 & 56 & 64 \\
\hline Fasting blood glucose (mg/dL) & $159.2 \pm 41.5$ & $152.7 \pm 43.5$ & $156.6 \pm 35.4$ & $166.5 \pm 38.7$ & $173.5 \pm 48.1$ & $154.1 \pm 38.3$ & $146.0 \pm 43.3$ & $158.9 \pm 36.5$ \\
\hline HOMA-IR & $2.83 \pm 1.80$ & $2.36 \pm 1.45$ & $2.70 \pm 1.69$ & $2.97 \pm 1.92$ & $3.34 \pm 1.72$ & $2.68 \pm 2.03$ & $2.69 \pm 1.75$ & $3.01 \pm 2.03$ \\
\hline HOMA- $\beta$ (\%) & $32.1 \pm 27.1$ & $32.6 \pm 33.9$ & $29.4 \pm 20.1$ & $33.4 \pm 25.7$ & $31.5 \pm 22.7$ & $29.1 \pm 21.3$ & $36.0 \pm 35.2$ & $33.0 \pm 25.3$ \\
\hline C-Peptide (ng/mL) & $2.10 \pm 0.89$ & $2.10 \pm 0.90$ & $2.36 \pm 1.64$ & $2.08 \pm 0.58$ & $2.14 \pm 0.74$ & $1.97 \pm 0.78$ & $2.00 \pm 0.74$ & $2.05 \pm 0.96$ \\
\hline $\mathrm{SBP}(\mathrm{mmHg})$ & $130.9 \pm 14.9$ & $128.9 \pm 16.1$ & $134.0 \pm 13.4$ & $131.8 \pm 11.4$ & $131.0 \pm 16.5$ & $131.6 \pm 16.3$ & $130.5 \pm 13.4$ & $131.4 \pm 13.8$ \\
\hline $\mathrm{DBP}(\mathrm{mmHg})$ & $76.5 \pm 10.5$ & $75.7 \pm 9.7$ & $76.5 \pm 9.5$ & $77.3 \pm 10.3$ & $79.6 \pm 11.9$ & $76.8 \pm 11.4$ & $79.7 \pm 12.0$ & $75.1 \pm 10.2$ \\
\hline Hypertension & $393(60.4)$ & $107(56.6)$ & $46(63.9)$ & $29(58)$ & $60(60.6)$ & $24(63.2)$ & $13(72.2)$ & $114(61.6)$ \\
\hline Dyslipidemia & $417(64.1)$ & $102(54)$ & $41(56.9)$ & $34(68)$ & $72(72.7)$ & $25(65.8)$ & $12(66.7)$ & $131(70.8)$ \\
\hline Hyperuricemia & $65(10)$ & $17(9)$ & $4(5.6)$ & $2(4)$ & $13(13.1)$ & $5(13.2)$ & $7(38.9)$ & $17(9.2)$ \\
\hline Retinopathy & $48(7.4)$ & $7(3.7)$ & $3(4.2)$ & $2(4)$ & $18(18.2)$ & $1(2.6)$ & $3(16.7)$ & $14(7.6)$ \\
\hline Arteriosclerosis obliterans & $55(8.4)$ & $8(4.2)$ & $2(2.8)$ & $2(4)$ & $25(25.3)$ & $2(5.3)$ & $2(11.1)$ & $14(7.6)$ \\
\hline Atrial fibrillation & $16(2.5)$ & $5(2.6)$ & $2(2.8)$ & $2(4)$ & $2(2)$ & $1(2.6)$ & $0(0)$ & $4(2.2)$ \\
\hline Renal disease & $49(7.5)$ & $5(2.6)$ & $2(2.8)$ & $2(4)$ & $16(16.2)$ & $3(7.9)$ & $4(22.2)$ & $17(9.2)$ \\
\hline Hepatic disease & $56(8.6)$ & $15(7.9)$ & $3(4.2)$ & $4(8)$ & $14(14.1)$ & $4(10.5)$ & $3(16.7)$ & $13(7)$ \\
\hline Myocardial infarction & $18(2.8)$ & $5(2.6)$ & $2(2.8)$ & $1(2)$ & $3(3)$ & $0(0)$ & $2(11.1)$ & $5(2.7)$ \\
\hline Cerebral stroke & $45(6.9)$ & $8(4.2)$ & $4(5.6)$ & $3(6)$ & $6(6.1)$ & $3(7.9)$ & $4(22.2)$ & $17(9.2)$ \\
\hline Angina pectoris & $27(4.1)$ & $9(4.8)$ & $2(2.8)$ & $3(6)$ & $6(6.1)$ & $1(2.6)$ & $1(5.6)$ & $5(2.7)$ \\
\hline Cardiac failure & $11(1.7)$ & $3(1.6)$ & $3(4.2)$ & $1(2)$ & $1(1)$ & $0(0)$ & $0(0)$ & $3(1.6)$ \\
\hline
\end{tabular}

Data presented as $n(\%)$ or mean $\pm S D$ 


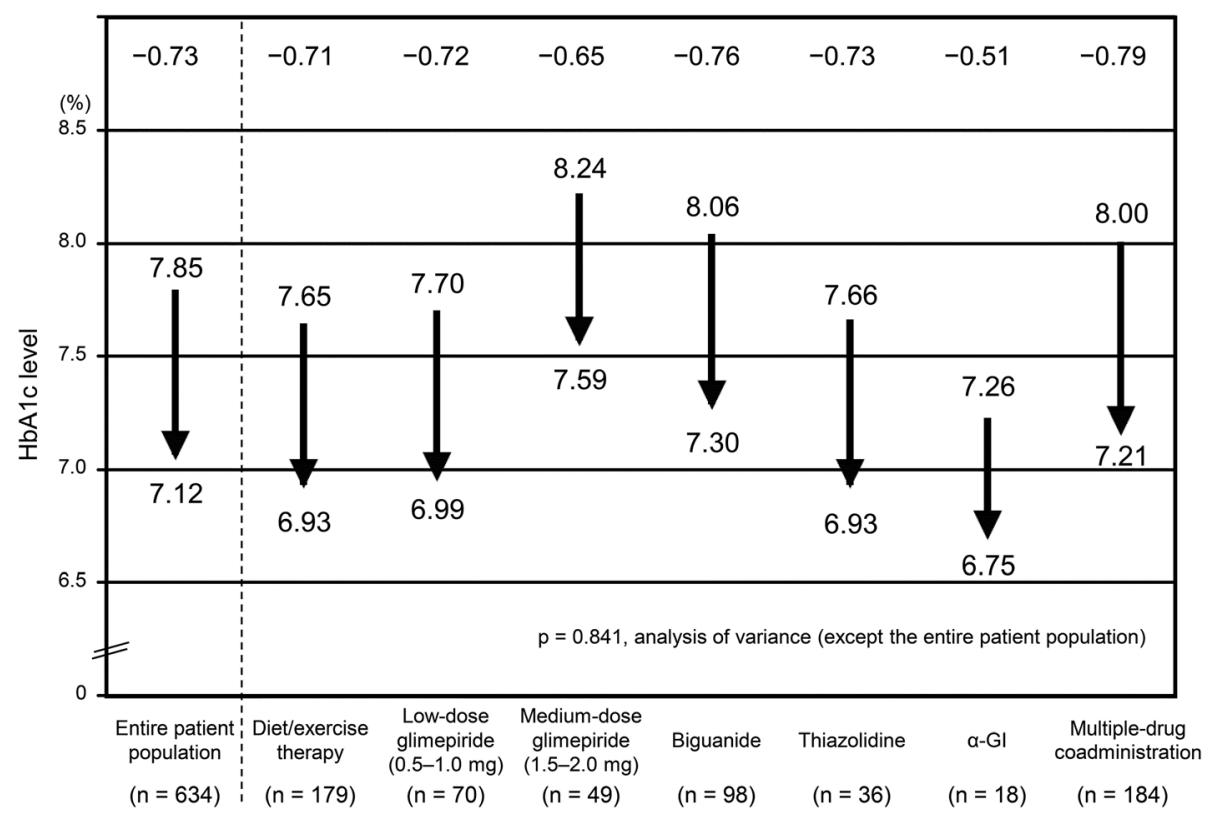

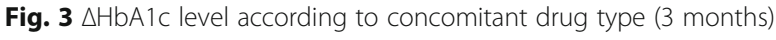

co-administration group), urticaria (multiple-drug coadministration group), were judged by the investigator to be causally related to the study drug. The incidence of an adverse drug reaction was $0.56 \%$. Hypoglycemia occurred in three patients $(0.42 \%)$, but all the cases were mild. They were judged to be causally related to the study drug in one patient each in the multiple drug co-administration and low-dose glimepiride groups, and as possibly causally related to the study drug in one patient in the sitagliptin single-drug group.

\section{Discussion}

In the present study, the overall sitagliptin-induced decrease $(95 \% \mathrm{CI})$ in $\mathrm{HbA} 1 \mathrm{c}$ level from baseline was $-0.73 \%$ (range, -0.80 to -0.67 ) at 3 months. In many studies, sitagliptin reportedly improved $\mathrm{HbA1c}$ and fasting blood glucose levels both as a single-drug therapy $[3,8-10]$ and as a combination therapy with other antidiabetic drugs $[4,5,11]$. In our study, we excluded patients undergoing insulin use, also some clinical trials [12, 13] reported about the combination therapy about sitagliptin and insulin. The patients in the present study had chronic diabetes mellitus, and many had already been inadequately controlled with antidiabetic drugs and additionally received sitagliptin. This suggests that the conditions under which this study was conducted were closer to routine clinical practice than those of another Japanese dose-finding study for sitagliptin [9]. Our study showed favorable, significant results for patients taking sitagliptin, which were similar to those obtained in other studies, despite the differences in study conditions.
In the present study, no significant difference in the change in HbA1c level was observed between the groups of patients who received different concomitant drugs. However, the extent of the improvement was greater in the patients with a higher baseline HbA1c level [S3]. This suggests the need to correct for the effect of the baseline HbA1c level when interpreting data obtained in studies with widely scattered baseline HbA1c values. Sitagliptin-induced improvement in the HbA1c level was more difficult to achieve in the medium-dose glimepiride group than in the other groups, based on the exploratory study on the factors that affect the blood glucose-lowering effect of sitagliptin, the multiple regression analysis of the correlation between the baseline $\mathrm{HbA1c}$ level and the change in HbA1c level from baseline based on the deviation from the approximate linear correlation (Table 3). The baseline HbA1c level in the medium-dose glimepiride group was high (8.24\%), but the sitagliptin-induced improvement in $\mathrm{HbA1c}$ level failed to meet the expectation that the higher the baseline HbA1c level, the greater the improvement $[14,15]$. Although there is no report stating that Glimepiride is likely to cause the secondary failure, in comparison with Sulfonylurea, Biguanide and Thiazolidinedione, it is reported that Sulfonylurea causes the secondary failure [2]. Although Glimepiride doesn't beget the secondary failure easily in Sulfonylurea [16], compared to other drug groups in this study, it is also presumed that in Glimepiride middle-dose group, the pancreas may become exhausted. We can't identify the cause of it because there were some patients who didn't laboratory test. 
Table 2 Laboratory test results

\begin{tabular}{|c|c|c|c|c|c|c|c|c|}
\hline Parameter & $n$ & $\begin{array}{l}0 \text { month } \\
(\text { mean } \pm \text { SE) }\end{array}$ & $n$ & $\begin{array}{l}3 \text { months (mean } \pm \text { SE) } \\
\Delta 3 \text { months, mean }(95 \% \mathrm{Cl})\end{array}$ & $p$ & $n$ & $\begin{array}{l}12 \text { months (mean } \pm \mathrm{SE}) \\
\Delta 12 \text { months, mean }(95 \% \mathrm{Cl})\end{array}$ & $p$ \\
\hline $\mathrm{HbA1c}$ & 649 & $7.86 \pm 0.04$ & $\begin{array}{l}635 \\
634\end{array}$ & $\begin{array}{l}7.12 \pm 0.04 \\
-0.73(-0.80,-0.67)\end{array}$ & $0.001>$ & $\begin{array}{l}577 \\
576\end{array}$ & $\begin{array}{l}7.11 \pm 0.04 \\
-0.69(-0.76,-0.62)\end{array}$ & $0.001>$ \\
\hline Converted mean $\mathrm{HbA} 1 \mathrm{c}(\mathrm{mmol} / \mathrm{mol})$ & & 62 & & 54 & & & 54 & \\
\hline Fasting blood glucose & 493 & $159.2 \pm 1.9$ & $\begin{array}{l}446 \\
413\end{array}$ & $\begin{array}{l}135.1 \pm 1.6 \\
-26.3(-29.7,-22.9)\end{array}$ & $0.001>$ & $\begin{array}{l}394 \\
361\end{array}$ & $\begin{array}{l}135.9 \pm 1.7 \\
-23.2(-27.3,-19.2)\end{array}$ & $0.001>$ \\
\hline HOMA-R & 384 & $2.83 \pm 0.09$ & $\begin{array}{l}367 \\
318\end{array}$ & $\begin{array}{l}2.71 \pm 0.14 \\
-0.36(-0.51,-0.22)\end{array}$ & $0.001>$ & $\begin{array}{l}331 \\
275\end{array}$ & $\begin{array}{l}2.66 \pm 0.11 \\
-0.29(-0.47,-0.10)\end{array}$ & 0.002 \\
\hline HOMA- $\beta$ & 382 & $32.1 \pm 1.4$ & $\begin{array}{l}364 \\
315\end{array}$ & $\begin{array}{l}47 \pm 3.2 \\
11.5(8.4,14.6)\end{array}$ & $0.001>$ & $\begin{array}{l}324 \\
270\end{array}$ & $\begin{array}{l}43.9 \pm 2 \\
11.1(7.6,14.6)\end{array}$ & $0.001>$ \\
\hline Fasting insulin & 384 & $7.22 \pm 0.21$ & $\begin{array}{l}367 \\
318\end{array}$ & $\begin{array}{l}8.09 \pm 0.43 \\
0.21(-0.15,0.57)\end{array}$ & 0.254 & $\begin{array}{l}331 \\
275\end{array}$ & $\begin{array}{l}7.77 \pm 0.29 \\
0.29(-0.10,0.67)\end{array}$ & 0.147 \\
\hline $1.5 \mathrm{AG}$ & 254 & $6.4 \pm 0.3$ & $\begin{array}{l}248 \\
240\end{array}$ & $\begin{array}{l}11.3 \pm 0.4 \\
4.8(4.3,5.2)\end{array}$ & $0.001>$ & $\begin{array}{l}213 \\
207\end{array}$ & $\begin{array}{l}10.2 \pm 0.4 \\
3.8(3.2,4.3)\end{array}$ & $0.001>$ \\
\hline Glycoalbumin & 254 & $21.1 \pm 0.2$ & $\begin{array}{l}248 \\
240\end{array}$ & $\begin{array}{l}18.2 \pm 0.2 \\
-2.7(-3.1,-2.4)\end{array}$ & $0.001>$ & $\begin{array}{l}213 \\
207\end{array}$ & $\begin{array}{l}18.5 \pm 0.2 \\
-2.5(-2.9,-2.2)\end{array}$ & $0.001>$ \\
\hline C-Peptide & 200 & $2.1 \pm 0.06$ & $\begin{array}{l}197 \\
177\end{array}$ & $\begin{array}{l}2.07 \pm 0.06 \\
0(-0.11,0.1)\end{array}$ & 0.925 & $\begin{array}{l}152 \\
137\end{array}$ & $\begin{array}{l}2.17 \pm 0.08 \\
0.05(-0.06,0.15)\end{array}$ & 0.380 \\
\hline Proinsulin-to-insulin ratio & 193 & $0.51 \pm 0.02$ & $\begin{array}{l}187 \\
169\end{array}$ & $\begin{array}{l}0.45 \pm 0.02 \\
-0.05(-0.08,-0.02)\end{array}$ & 0.033 & $\begin{array}{l}150 \\
135\end{array}$ & $\begin{array}{l}0.49 \pm 0.02 \\
-0.01(-0.05,0.03)\end{array}$ & 0.857 \\
\hline $\mathrm{CPI}$ & 200 & $1.38 \pm 0.05$ & $\begin{array}{l}197 \\
177\end{array}$ & $\begin{array}{l}1.56 \pm 0.05 \\
0.23(0.15,0.32)\end{array}$ & $0.001>$ & $\begin{array}{l}152 \\
137\end{array}$ & $\begin{array}{l}1.66 \pm 0.07 \\
0.28(0.18,0.38)\end{array}$ & $0.001>$ \\
\hline SBP & 646 & $130.9 \pm 0.6$ & $\begin{array}{l}635 \\
634\end{array}$ & $\begin{array}{l}129.3 \pm 0.6 \\
-1.7(-2.9,-0.6)\end{array}$ & 0.004 & $\begin{array}{l}576 \\
575\end{array}$ & $\begin{array}{l}130.2 \pm 0.6 \\
-0.3(-1.6,0.9)\end{array}$ & 0.587 \\
\hline $\mathrm{DBP}$ & 646 & $76.5 \pm 0.4$ & $\begin{array}{l}635 \\
634\end{array}$ & $\begin{array}{l}75.3 \pm 0.4 \\
-1.2(-1.9,-0.4)\end{array}$ & 0.003 & $\begin{array}{l}576 \\
575\end{array}$ & $\begin{array}{l}75.6 \pm 0.4 \\
-0.9(-1.7,-0.1)\end{array}$ & 0.022 \\
\hline BMl & 630 & $25.19 \pm 0.17$ & $\begin{array}{l}601 \\
599\end{array}$ & $\begin{array}{l}25.24 \pm 0.17 \\
0(-0.10,0.05)\end{array}$ & 0.987 & $\begin{array}{l}552 \\
549\end{array}$ & $\begin{array}{l}25.1 \pm 0.18 \\
-0.08(-0.20,0)\end{array}$ & 0.064 \\
\hline Triglycerides & 589 & $149.3 \pm 4.1$ & $\begin{array}{l}569 \\
551\end{array}$ & $\begin{array}{l}146.7 \pm 5.1 \\
-6.1(-13.0,0.7)\end{array}$ & 0.081 & $\begin{array}{l}537 \\
517\end{array}$ & $\begin{array}{l}142.5 \pm 4.2 \\
-8.9(-16.0,-1.3)\end{array}$ & 0.021 \\
\hline $\mathrm{HDL}-\mathrm{C}$ & 574 & $55 \pm 0.6$ & $\begin{array}{l}555 \\
537\end{array}$ & $\begin{array}{l}53.8 \pm 0.6 \\
-1.1(-1.8,-0.5)\end{array}$ & 0.001 & $\begin{array}{l}527 \\
506\end{array}$ & $\begin{array}{l}53.6 \pm 0.6 \\
-1.6(-2.3,-0.9)\end{array}$ & $0.001>$ \\
\hline LDL-C & 589 & $113.9 \pm 1.2$ & $\begin{array}{l}563 \\
545\end{array}$ & $\begin{array}{l}110 \pm 1.2 \\
-3.2(-4.9,-1.5)\end{array}$ & $0.001>$ & $\begin{array}{l}533 \\
512\end{array}$ & $\begin{array}{l}110.3 \pm 1.2 \\
-3.4(-5.6,-1.2)\end{array}$ & 0.003 \\
\hline
\end{tabular}

Upper row: Observed value (mean $\pm \mathrm{SE})$

Lower row: Change (mean [95\% Cl])

$p$-value: versus 0 month, paired $t$-test

However the duration of Glimepiride middle-dose group was 10.2 years, it was longer than overall. Consequently, the effect of sitagliptin might not be obtained easily. By contrast, in a study where glimepiride was administered at a low or high dose and sitagliptin was added after dose reduction of glimepiride [17], sufficient efficacy was achieved in both groups. Patients in actual clinical settings have diverse treatment histories, which requires future studies on sitagliptin co-administration with medium- or high-dose glimepiride. Although, smoking and drinking rate are both high in the medium-dose glimepiride group. But we judged it is not significant elements in the multiple regression analysis.

To prevent complications, the target HbAlc level is $<7.0 \%(53 \mathrm{mmol} / \mathrm{mol})$ and the target fasting blood glucose level is $130 \mathrm{mg} / \mathrm{dL}$ for blood glucose control [6]. In the present study, the rate of achieving the target control level improved for both HbA1c and fasting blood glucose levels.

Laboratory test results showed that the homeostatic model of assessment ( $\beta$ index) significantly increased at 3 month after starting treatment compared with its baseline value, suggesting that sitagliptin enhances insulin secretion.

Patients with type 2 diabetes mellitus have reduced numbers of pancreatic $\beta$ cells $[18,19]$. In an animal experiment, sitagliptin reportedly had pancreatic $\beta$ cell-protecting and growth-promoting effects [20], in our present study, the Cpeptide reactivity index (CPI) significantly increased at 3 months after starting treatment. It was more likely because of improved beta-cell function rather than increased beta-cell mass because it was just 3 months after the start 
Table 3 Single and multiple regression analyses of baseline $\mathrm{HbA} 1 \mathrm{c}$ and $\triangle \mathrm{HbA} 1 \mathrm{c}$ levels (at 3 months) using the deviation from the approximate linear correlation coefficient as the dependent variable

\begin{tabular}{|c|c|c|c|c|c|c|c|c|}
\hline \multirow{3}{*}{ Independent variable } & \multicolumn{4}{|c|}{ Single regression analysis } & \multicolumn{4}{|c|}{ Multiple regression analysis } \\
\hline & \multirow{2}{*}{$\begin{array}{l}\text { Regression } \\
\text { coefficient }\end{array}$} & \multirow{2}{*}{$\begin{array}{l}\text { Lower } \\
\text { Limit }\end{array}$} & \multirow{2}{*}{$\begin{array}{l}\text { Upper } \\
\text { Limit }\end{array}$} & \multirow[t]{2}{*}{$P$-value } & \multirow{2}{*}{$\begin{array}{l}\text { Partial } \\
\text { regression } \\
\text { coefficient }\end{array}$} & \multirow{2}{*}{$\begin{array}{l}\text { Lower } \\
\text { Limit }\end{array}$} & \multirow{2}{*}{$\begin{array}{l}\text { Upper } \\
\text { Limit }\end{array}$} & \multirow[t]{2}{*}{$P$-value } \\
\hline & & & & & & & & \\
\hline Age & 0.006 & 0.002 & 0.011 & $0.008^{\ddagger}$ & 0.004 & -0.001 & 0.009 & 0.149 \\
\hline Sex (male) & -0.022 & -0.140 & 0.096 & 0.715 & & & & \\
\hline Smoking habit & 0.015 & -0.121 & 0.151 & 0.83 & & & & \\
\hline Drinking habit & -0.037 & -0.152 & 0.078 & 0.523 & & & & \\
\hline Duration of diabetes mellitus & -0.004 & -0.012 & 0.005 & 0.377 & & & & \\
\hline Body mass index & -0.015 & -0.028 & -0.001 & $0.029^{\ddagger}$ & -0.009 & -0.023 & 0.005 & 0.207 \\
\hline Mean blood pressure & -0.008 & -0.013 & -0.002 & $0.005^{\ddagger}$ & -0.004 & -0.008 & 0.001 & 0.095 \\
\hline Diet/exercise group & 0.097 & -0.027 & 0.22 & 0.126 & & & & \\
\hline Low-dose glimepiride group & 0.054 & -0.124 & 0.232 & 0.555 & & & & \\
\hline Medium-dose glimepiride group & -0.264 & -0.472 & -0.056 & $0.013^{\ddagger}$ & -0.249 & -0.452 & -0.045 & $0.017^{\S}$ \\
\hline Biguanide group & -0.073 & -0.228 & 0.081 & 0.351 & & & & \\
\hline Thiazolidine group & 0.082 & -0.159 & 0.323 & 0.504 & & & & \\
\hline aGl group & 0.028 & -0.308 & 0.364 & 0.871 & & & & \\
\hline Multi-drug coadministration group & -0.008 & -0.131 & 0.115 & 0.9 & & & & \\
\hline
\end{tabular}

${ }^{\mp} p<0.05$, single regression analysis

${ }^{s_{p}} p<0.05$, multiple regression analysis

of sitagliptin, and considering this was an observation in human subjects. However, Nishimura et al. reported that CPI increased from baseline to $3,6,12,18$, and 24 months after the start of sitagliptin administration [21]. This indicated the pancreatic $\beta$ cell-protective effect of sitagliptin in a clinical setting. Nishimura et al.also reported that greater CPI increase after sitagliptin administration were associated with the response to sitagliptin [21]. In our study, the number of patients who test CPI was limited. So we didn't analysis CPI as the elements of logistic analysis. But CPI may be benchmark of the efficacy of Sitagliptin.

However, the insulin secretion-enhancing effect of glucagon-like peptide 1 is reportedly dependent on the blood glucose level [22]. A meta-analysis on the effect of DPP-4 inhibitors revealed that the hypoglycemic risk from DPP-4 inhibitors is similar to that from placebo or thiazolidines but lower than that from sulfonylurea drugs [23]. Sitagliptin did not induce excessive hypoglycemia [10], and in the present study, mild hypoglycemia occurred in only three patients.
DPP-4 inhibitors do not induce body weight increases $[8,24-26]$. In the present study, sitagliptin did not cause any increase in the body mass index. Sitagliptin also decreases postprandial triglyceride level [27] and lowers blood pressure, blood lipid level [28] and alkaline phosphatase level [29]. Our present study also showed decreased systolic and diastolic blood pressures, decreased LDL-C level and decreased triglyceride levels, which is similar to results from previously published studies.

Incretin is secreted from the gastrointestinal tract by the stimulation of molecules such as glucose and fats that are produced after food is taken into the digestive organs. Thus, incretin enhances insulin secretion from the pancreatic $\beta$ cells when the blood glucose level increases after a meal. By contrast, sitagliptin decreased both postprandial and fasting blood glucose levels [26]. In the present study, sitagliptin improved fasting blood glucose levels and the rate of achieving the target control level. Talk about adherence, Walker et al. reported $22 \%$ of DM patients are defined as poor adherence of

Table 4 Changes in antidiabetic medication during the study (After 3 months of follow-up) $n=585$

\begin{tabular}{llllll}
\hline Agent & Sulfonylurea & Biguanide & Thiazolidinedione & a-Glucosidase inhibitors & Sitagliptin \\
\hline Patients who received additional antidiabetic agent(s) & 26 & 18 & 9 & 2 & 0 \\
Patients who increased dosage & 8 & 26 & 0 & 0 & 86 \\
Patients who decreased dosage & 7 & 4 & 0 & 0 & 2 \\
Patients who stopped receiving agent(s) & 8 & 3 & 20 & 0 & 0 \\
\hline
\end{tabular}


Table 5 Summary of adverse events

\begin{tabular}{ll}
\hline Hypoglycemia & 3 \\
Hyperglycemia & 1 \\
Hematopoietic disorders & 3 \\
Cardiovascular disease & 8 \\
Respiratory disorders & 2 \\
Skin eruption & 2 \\
Gastrointestinal disorders & 5 \\
Hepatobiliary disorders & 7 \\
Renal and urinary disorders & 2 \\
Neuropsychiatric disorders & 2 \\
Others & 20 \\
Total & 55 \\
\hline
\end{tabular}

medicine [30], but our study showed only $5.7 \%$ of poor adherence of sitagliptin.

We designed this study period because Iwamoto et al. reported that clinical treatment with sitagliptin for 12 weeks provided significant and clinically meaningful reductions in HbA1c. Although, if study drug doesn't work enough, to fix medication for a long time is not good for patients. On the other hand, Nishimura et al. reported that a patient's HbA1c change at 3 months may be a predictor of their HbA1c change at 24 months [11]. And our study also showed the HbA1c level of 12 month was similar to 3 month. According to the result of this study, we assume that 3 months of observation period is not too short to evaluate the clinical effects of sitagliptin.

\section{Study limitations}

This was an open-label observational study (patients were not allocated to the groups), the number of patients were different in the each groups because we categorized by the type of pre-existing therapy for type 2 diabetes. In this study, we excluded participants undergoing insulin use and rapid-acting insulin secretagogues. Dose increases of sitagliptin, and additional administration, dose changes or discontinuation of other antidiabetic drugs were allowed starting after 3 months of treatment. This short duration is a limitations to assessing the long-term usefulness of sitagliptin administration. However, this study is significant in that it evaluated sitagliptin efficacy in patients treated with different concomitant drugs in actual clinical settings.

\section{Conclusion}

Sitagliptin administration improved the HbA1c level and the rate of achieving the target control levels in patients with type 2 diabetes mellitus who were previously untreated with, or who were poorly responsive to, existing antidiabetic drugs. Thus, sitagliptin is expected to be effective for this patient group. Concomitant administration of sitagliptin to patients treated with medium-dose glimepiride only slightly improved blood glucose control after correction for the baseline HbA1c level.

\section{Additional files}

Additional file 1: Figure S1. $\mathrm{HbA} 1 \mathrm{C}$ level and changes over time. (TIF $160 \mathrm{~kb}$ )

Additional file 2: Figure S2. Rate of achieving the target fasting blood glucose level ( $\mathrm{HbA1c}$ level). (TIF $268 \mathrm{~kb}$ )

Additional file 3: Correlation between baseline $\mathrm{HbA} 1 \mathrm{c}$ level and change in $\mathrm{HbA1c}$ level after 3 months of treatment. (Strongly effective: Below the correlation line; Weakly effective: Above the correlation line). (TIF 113 kb)

\section{Abbreviations}

95\% Cl: 95\% Confidence interval; BMl: Body mass index; CPI: C-peptide reactivity index; DBP: Diastolic blood pressure; DPP-4: Dipeptidyl peptidase-4; HbA1c: Glycated hemoglobin; HDL-C: High-density lipoprotein cholesterol; LDL-C: Low-density lipoprotein cholesterol; MHLW: Ministry of Health, Labour and Welfare of Japan; NGSP: National Glycohemoglobin Standardization Program; SBP: Systolic blood pressure; SD: Standard deviation; SE: Standard error; TG: Triglycerides; a-Gl: a-glucosidase inhibitors

\section{Acknowledgments}

We would like to express our sincere gratitude to Mr. Shogo Shishikura (MSD K.K.,) (Teikyo University Graduate School of Public Health, MPH) for scientific advice including references for revising the manuscript. We also would like to thank and Nouvelle Place Inc. for conducting the data analyses.

\section{Funding}

This study was funded by Japan Diabetes Foundation.

Availability of data and materials

Data are available on request to the authors.

Authors' contributions

Conceived and designed the experiments: HS NH KS HO SH NU TK OT HN MH Yl; Enrolled patients: HS NH KS HO NU TK OT HN MH; Analyzed the data: HS Yl; Wrote the first draft of the manuscript: HS Yl; Contributed to the writing of the manuscript: HS NH KS HO SH NU TK OT HN MH Yl; Agree with manuscript results and conclusions: HS NH KS HO SH NU TK OT HN MH YI. All authors read and approved the final manuscript.

\section{Competing interest}

Hiroshi Sakura received honoraria from Mitsubishi Tanabe Pharma Corporation and research grant from Ono Pharmaceutical Co., Ltd. Other authors declare that they have no conflict of interest.

\section{Consent for publication}

Not applicable.

\section{Ethics approval and consent to participate}

Written informed consent was obtained from all individual participants included in the study. This study was conducted with the approval of the ethic committee of the Tokyo Women's Medical University (UMIN000019154) and all procedures performed in studies involving human participants were in accordance with the ethical standards of the institutional and/or national research committee and with the 1964 Helsinki declaration and its later amendments or comparable ethical standards.

\section{JAMP Study Investigators}

The following investigators were involved in this study: Akiko Sato (Maruyama Internal Medicine Clinic); Akinori Yamashita (Yamashita Clinic); Akira Miyashita (Miyashita Surgery Clinic); Asako Kokubo (Kokubo Clinic); Atsuro Tsuchiya (Tsuchiya Clinic); Dai Hirohara (Hanazono Clinic); Daiji Kogure (Kogure Clinic); Daijo Kasahara (Kasahara Clinic); Hideki Tanaka (Internal Medicine, Seiwa Clinic); Hideki Tanaka (Internal Medicine, Nishiarai Hospital); Hideo Tezuka (Tezuka Clinic); Hiroyuki Kuroki (Internal Medicine, Johsai 
Hospital); Jun Ogino (Department of Diabetes, Endocrine and Metabolic Diseases, Tokyo Women's Medical University Yachiyo Medical Center); Kanu Kin (Internal Medicine, Nishiarai Lifestyle-related diseases Clinic); Kanu Kin (Internal Medicine, Nishiarai Hospital); Kazuko Muto (Tokyo Women's Medical University); Kazuo Suzuki (Kenkokan Suzuki Clinic of Internal Medicine); Keiko Iseki (Iseki Clinic); Keita Watanabe (Watanabe Clinic); Kenshi Higami (Higami Hospital); Kenzo Matsumura (Matsumura Gastroenterological Clinic); Kiyotaka Nakajima (Ebisu Clinic); Koki Shin (Shin Clinic); Kuniya Koizumi (Kuniya Clinic); Maki Saneshige (Mugishima Medical Clinic); Makio Sekine (Sekine Clinic); Makoto Yaida (Urban Heights Clinic); Mari Kiuchi (Physician, Kanauchi Medical Clinic); Mari Mugishima (Mugishima Medical Clinic); Mari Osawa (Department of Diabetes Mellitus, Institute of Geriatrics, Tokyo Women's Medical University); Masae Banno (Banno Medical Clinic); Masahiro Yamamoto (Internal Medicine 1, Shimane University Faculty of Medicine); Masatake Hiratsuka (Higashishinagawa Clinic); Masumi Hosoya (Yasui Clinic); Michika Atsuta (Internal Medicine, Nishiarai Lifestyle-related diseases Clinic); Mitsutoshi Kato (Kato Clinic of Internal Medicine); Miwa Morita (Internal Medicine 1, Shimane University Faculty of Medicine); Munehiro Miyamae (Johsai Hospital); Mutsumi lijima (Abe Hospital); Naomi Okuyama (Shinjuku Mitsui Building Clinic); Nobuo Hisano (Mejiro Medical Clinic); Norihiro Tsuchiya (Omotesando Naika Ganka); Rie Wada (Kanauchi Medical Clinic); Rie Wada (Nerimasakuradai Clinic); Ryuji Momose (Momo Medical Clinic); Sachiko Otake (Tokyo Women's Medical University); Satoko Maruyama (Shinjuku Mitsui Building Clinic); Satoru Takada (Internal Medicine, Social welfare corporation Shineikai Takinogawa Hospital); Shigeki Dan (Ube Internal Medicine and Pediatrics Hospital); Shigeki Nishizawa (Nishizawa Medical Clinic); Shigeo Yamashita (Department of Diabetes and Endocrinology, JR Tokyo General Hospital); Shingo Saneshige (Internal Medicine, Kamiochiai Shin Clinic); Shinichi Teno (Teno Clinic); Shinji Tsuruta (Diabetic Medicine, Itabashi Chuo Medical Center); Shinobu Kumakura (Kumakura Medical Clinic); Sumiko Kijima (Abe Hospital); Takashi Kondo (Kondo Clinic); Takeo Onishi (Internal Medicine, Onishi Clinic); Taku Kudo (Internal Medicine, Social welfare corporation Shineikai Takinogawa Hospital); Tatsushi Sugiura (Internal Medicine, Seiwa Clinic); Toshihiko Ishiguro (Kaname Clinic); Yasue Suzuki (Suzuki Medical Clinic); Yasuhiro Tomita (Nakanobu Clinic); Yasuko Takano (Department of Diabetes, Shiseikai Daini Hospital); Yoshihisa Akimoto (Akimoto Yoshi Medical Clinic); Yoshiko Odanaka (Ito Internal Medicine Pediatrics Clinic); Yoshimasa Tasaka (Tokyo Women's Medical University); Yoshitaka Aiso (Internal Medicine, Diabetes, Aiso Clinic); Yukiko Inoue (Inoue Medical Clinic); Yukinobu Kobayashi (Kobayashi Clinic).

\section{Author details}

'Department of Medicine, Medical Center East, Tokyo Women's Medical University School of Medicine, 2-1-10 Nishiogu, Arakawa-ku, Tokyo 116-8567, Japan. ${ }^{2}$ Department of Diabetes, Endocrine and Metabolic Diseases, Tokyo Women's Medical University Yachiyo Medical Center, 477-96, Owada-shinden, Yachiyo-shi, Chiba 276-8524, Japan. Internal Medicine, Suzuki Clinic, 2-10-14, Koyasu-machi, Hachioji-shi, Tokyo 192-0904, Japan. ${ }^{4}$ Internal Medicine, Oyama East Clinic, 1-32-1, Ekihigashi-dori, Oyama-shi, Tochigi 323-0022, Japan. ${ }^{5}$ Internal Medicine, Nishiyamado-Keiwa Hospital, 3247-1, Kounosu, Naka-shi, Ibaraki 311-0133, Japan. 'Department of Medicine, Diabetes Center, Institute of Geriatrics, Tokyo Women's Medical University, Shibuya Cross Tower 22F, 2-15-1, Shibuya, Shibuya-ku, Tokyo 150-0002, Japan. ${ }^{7}$ Josai Hospital, 2-42-11, Kamiogi, Suginami-ku, Tokyo 167-0043, Japan. ${ }^{8}$ Diabetes and Lifestyle Center, Tomonaga Clinic, Shinyon curumu Building 9F, 4-2-23, Shinjuku, Shinjuku-ku, Tokyo 160-0022, Japan. ${ }^{9}$ Diabetes Center, Edogawa Hospital, Medical Plaza Shinozaki, SK Building, 7-15-12, Shinozaki-machi, Edogawa-ku, Tokyo 133-0057, Japan. ${ }^{10}$ Nishikawa Clinic, 2-16-3, Towa, Adachi-ku, Tokyo 120-0003, Japan. ${ }^{11}$ The Institute for Adult Diseases, Asahi Life Foundation, Asahiseimeisunaga building, 2-2-6, Nihonbashi Bakuro-cho, Chuo-ku, Tokyo 103-0002, Japan.

\section{Received: 26 July 2016 Accepted: 18 November 2016}

\section{Published online: 01 December 2016}

\section{References}

1. Results of "National Health and Nutrition Survey". Ministry of Health, Labour and Welfare. 2012. http://www.mhlw.go.jp/stf/houdou/0000032074.html.

2. Kahn SE, Haffner SM, Heise MA, et al. Glycemic durability of rosiglitazone, metformin, or glyburide monotherapy. N Engl J Med. 2006;355:2427-43. doi: 10.1056/NEJMoa066224.
3. Aschner P, Kipnes MS, Lunceford JK, Sanchez M, Mickel C, Williams-Herman DE. Effect of the dipeptidyl peptidase-4 inhibitor sitagliptin as monotherapy on glycemic control in patients with type 2 diabetes. Diabetes Care. 2006; 29:2632-7. doi:10.2337/dc06-0703.

4. Charbonnel B, Karasik A, Liu J, Wu M, Meininger G. Efficacy and safety of the dipeptidyl peptidase-4 inhibitor sitagliptin added to ongoing metformin therapy in patients with type 2 diabetes inadequately controlled with metformin alone. Diabetes Care. 2006;29:2638-43. doi:10.2337/dc06-0706.

5. Rosenstock J, Brazg R, Andryuk PJ, Lu K, Stein P. Efficacy and safety of the dipeptidyl peptidase-4 inhibitor sitagliptin added to ongoing pioglitazone therapy in patients with type 2 diabetes: a 24-week, multicenter, randomized, double-blind, placebo-controlled, parallel-group study. Clin Ther. 2006;28:1556-68. http://dx.doi.org/10.1016/j.clinthera.2006.10.007.

6. Evidence-based Practice Guideline for the Treatment for Diabetes in Japan. The Japan Diabetes Society. 2013. p. 21-30. http://www.jds.or.jp/modules/ en/index.php?content_id=44.

7. Seino Y, Nanjo K, Tajima N, et al. Report of the Committee on the classification and diagnostic criteria of diabetes mellitus. Japan Diabet Soc. 2012;55:485-504. DOl: http://doi.org/10.11213/tonyobyo.55.485.

8. Scott R, Wu M, Sanchez M, Stein P. Efficacy and tolerability of the dipeptidyl peptidase-4 inhibitor sitagliptin as monotherapy over 12 weeks in patients with type 2 diabetes. Int J Clin Pract. 2007;61:171-80. doi:10.1111/j.17421241.2006.01246.x

9. Iwamoto $Y$, Taniguchi T, Nonaka K, et al. Dose-ranging efficacy of sitagliptin, a dipeptidyl peptidase-4 inhibitor, in Japanese patients with type 2 diabetes mellitus. Endocr J. 2010;57:383-94. http://doi.org/10.1507/endocrj.K09E-272.

10. Iwamoto $Y$, Tajima N, Kadowaki T, et al. Efficacy and safety of sitagliptin monotherapy compared with voglibose in Japanese patients with type 2 diabetes: a randomized, double-blind trial. Diabetes Obes Metab. 2010;12: 613-22. doi:10.1111/j.1463-1326.2010.01197.x.

11. Nishimura T, Meguro S, Sekioka R, et al. A reduction of HbA1c after 3 months predicts 2-year responsiveness to sitagliptin treatment. Intern Med. 2015;54:2981-9. doi:10.2169/internalmedicine.54.4144.

12. Sato S, Saisho Y, Kou K, Meguro S, Tanaka M, Irie J, Kawai T, Itoh H. Efficacy and safety of sitagliptin added to insulin in Japanese patients with type 2 diabetes: the EDIT randomized trial. PLoS One. 2015;10:e0121988. doi:10. 1371/journal.pone.0121988.

13. Takai M, Ishikawa M, Maeda H, Kanamori A, Kubota A, Amemiya H, lizuka T, lemitsu K, Iwasaki T, Uehara G, Umezawa S, Obana M, Kaneshige H, Kaneshiro M, Kawata T, Sasai N, Saito T, Takuma T, Takeda H, Tanaka K, Tsurui N, Nakajima S, Hoshino K, Honda S, Machimura H, Matoba K, Minagawa F, Minami N, Miyairi Y, Mokubo A, Motomiya T, Waseda M, Miyakawa M, Naka Y, Terauchi Y, Tanaka Y, Matsuba I. Safety and efficacy of adding sitagliptin to insulin in patients with type 2 diabetes: the ASSIST-K study. Diabetes Res Clin Pract. 2014;103:e30-3. doi:10.1016/j.diabres.

14. Kubota A, Maeda H, Kanamori A, et al. Efficacy and safety of sitagliptin monotherapy and combination therapy in Japanese type 2 diabetes patients. $J$ Diabetes Invest. 2012;3:503-9. doi:10.1111/j.2040-1124.2012.00221.x.

15. Maeda H, Kubota A, Tanaka Y, Terauchi Y, Matsuba I, ASSET-K Study group. The safety, efficacy and predictors for $\mathrm{HbA1c}$ reduction of sitagliptin in the treatment of Japanese type 2 diabetes. Diabetes Res Clin Pract. 2012;95: e20-2. doi:10.1016/j.diabres.2011.10.011.

16. Kubota A, Yabe D, Kanamori A, et al. Factors influencing the durability of the glucose-lowering effect of sitagliptin combined with a sulfonylurea. J Diabetes Investig. 2014;5:445-8. doi:10.1111/jdi.12182.

17. Ishii H, Ohkubo Y, Takei M, et al. Efficacy of combination therapy with sitagliptin and low-dose glimepiride in Japanese patients with type 2 diabetes. J Clin Med Res. 2014;6:127-32. doi:10.14740/jocmr1701w.

18. Butler AE, Janson J, Bonner-Weir S, Ritzel R, Rizza RA, Butler PC. Beta-cell deficit and increased beta-cell apoptosis in humans with type 2 diabetes. Diabetes. 2003;52:102-10. doi:10.2337/diabetes.52.1.102.

19. Sakuraba H, Mizukami H, Yagihashi N, Wada R, Hanyu C, Yagihashi S. Reduced beta-cell mass and expression of oxidative stress-related DNA damage in the islet of Japanese Type II diabetic patients. Diabetologia. 2002;45:85-96. doi:10.1007/s001250200009.

20. Mu J, Woods J, Zhou YP, et al. Chronic inhibition of dipeptidyl peptidase-4 with a sitagliptin analog preserves pancreatic beta-cell mass and function in a rodent model of type 2 diabetes. Diabetes. 2006;55:1695-704. doi:10.2337/ db05-1602.

21. Nishimura T, Meguro S, Sekioka R, Tanaka K, Saisho Y, Irie J, Tanaka M, Kawai T, Itoh H. C-peptide immunoreactivity index is associated with improvement of 
HbA1c: 2-Year follow-up of sitagliptin use in patients with type 2 diabetes. Diabetes Res Clin Pract. 2015;108:441-7. doi:10.1016/j.diabres.2015.02.031.

22. Nauck MA, Heimesaat MM, Behle $K$, et al. Effects of glucagon-like peptide 1 on counterregulatory hormone responses, cognitive functions, and insulin secretion during hyperinsulinemic, stepped hypoglycemic clamp experiments in healthy volunteers. J Clin Endocrinol Metab. 2002;87:1239-46.

23. Monami M, lacomelli I, Marchionni N, Mannucci E. Dipeptydil peptidase-4 inhibitors in type 2 diabetes: a meta-analysis of randomized clinical trials. Nutr Metab Cardiovasc Dis. 2010;20:224-35. doi:10.1016/j.numecd.2009.03.015.

24. Kikuchi M, Abe N, Kato M, Terao S, Mimori N, Tachibana H. Vildagliptin dosedependently improves glycemic control in Japanese patients with type 2 diabetes mellitus. Diabetes Res Clin Pract. 2009;83:233-40. doi:10.1016/j. diabres.2008.10.006.

25. Rosenstock J, Baron MA, Dejager S, Mills D, Schweizer A. Comparison of vildagliptin and rosiglitazone monotherapy in patients with type 2 diabetes: a 24-week, double-blind, randomized trial. Diabetes Care. 2007;30:217-23. doi:10.2337/dc06-1815.

26. Nonaka K, Kakikawa T, Sato A, et al. Efficacy and safety of sitagliptin monotherapy in Japanese patients with type 2 diabetes. Diabetes Res Clin Pract. 2008;79:291-8. http://dx.doi.org/10.1016/j.diabres.2007.08.021.

27. Tremblay AJ, Lamarche B, Deacon CF, Weisnagel SJ, Couture P. Effect of sitagliptin therapy on postprandial lipoprotein levels in patients with type 2 diabetes. Diabetes Obes Metab. 2011;13:366-73. doi:10.1111/j.1463-1326. 2011.01362.x.

28. Shigematsu E, Yamakawa T, Kadonosono K, Terauchi Y. Effect of sitagliptin on lipid profile in patients with type 2 diabetes mellitus. J Clin Med Res. 2014;6:327-35. doi:10.14740/jocmr1889w.

29. Kubota A, Maeda H, Kanamori A, et al. Pleiotropic effects of sitagliptin in the treatment of type 2 diabetes mellitus patients. J Clin Med Res. 2012;4:30913. doi:10.4021/jocmr1061W.

30. Walker EA, Molitch M, Kramer MK, Kahn S, Ma Y, Edelstein S, Smith K, Johnson MK, Kitabchi A, Crandall J. Adherence to preventive medications: predictors and outcomes in the Diabetes Prevention Program. Diabetes Care. 2006;29:1997-2002

\section{Submit your next manuscript to BioMed Central and we will help you at every step:}

- We accept pre-submission inquiries

- Our selector tool helps you to find the most relevant journal

- We provide round the clock customer support

- Convenient online submission

- Thorough peer review

- Inclusion in PubMed and all major indexing services

- Maximum visibility for your research

Submit your manuscript at www.biomedcentral.com/submit

) Biomed Central 